\title{
PENGARUH CAMPURAN BIOETANOL PADA PERTALITE TERHADAP UNJUK KERJA (PERFORMA) MESIN OTTO 4 SILINDER
}

\author{
Ricko Yudhanta, ST, M.Sc \\ Dosen STTD \\ Jl. Raya Setu No. 89, Bekasi \\ Telp./Fax : (021) 8254640 \\ Ir. Juliaman P., M.Si \\ Dosen STTD \\ J1. Raya Setu No. 89, Bekasi \\ Telp./Fax : (021) 8254640
}

\author{
Sumantri W. Praja, ST, M.Sc \\ Dosen STTD \\ J1. Raya Setu No. 89, Bekasi \\ Telp./Fax : (021) 8254640 \\ DR. Ir. Djajadi, MM \\ Dosen STTD \\ J1. Raya Setu No. 89, Bekasi \\ Telp./Fax : (021) 8254640
}

\begin{abstract}
Against the background of the use of gasoline motors from year to year is increasing, this has resulted in the use of petroleum fuels is increasing and certainly very worrying, because with the increase in use of petroleum fuels, the petroleum reserves will decrease while the need for oil continues to grow. The above situation is also not in accordance with government policy in the energy sector, which seeks the use of petroleum fuels as economically as possible, considering that petroleum is a nonrenewable energy source. This energy crisis causes people to change their mindset to intensify research and use from non-renewable energy to renewable energy. Ethanol is a high-octane fuel that can be used to increase octane value in gasoline. Ethanol contains oxygen, thus perfecting fuel combustion with a positive effect minimizing air pollution. The fuel used for this study is pure pertalite $\left(E_{0}\right)$, 5\% bioethanol mixture + pertalite $95 \%$ $\left(E_{5}\right), 10 \%$ bioethanol mixture $+90 \%$ pertalite $\left(E_{10}\right), 15 \%$ bioethanol mixture $+85 \%$ pertalite $\left(E_{15}\right)$, and $20 \%$ bioethanol mixture + pertalite $80 \%\left(E_{20}\right)$. Mixing bioethanol on pertalite fuel can improve engine performance reaching the maximum point in $E_{15}$ fuel mixture, but mixing bioethanol above $15 \%$ performance tends to decrease. To get good engine performance, the best mixture is to mix $15 \%$ bioethanol into pertalite for cars over 15 years old. This is based on the average value of torque and power produced by each mixture of bioethanol fuel.
\end{abstract}

\section{Keyword : Car, Fuel,Octune,Bioethanol,Ethanol,Performance,engine}

\section{ABSTRAKSI}

Dilatar belakangi oleh pemakaian motor bensin dari tahun ke tahun semakin meningkat, hal ini mengakibatkan pemakaian bahan bakar minyak bumi semakin 
meningkat dan tentu sangat mengkhawatirkan, karena dengan peningkatan pemakaian bahan bakar minyak bumi, maka cadangan minyak bumi akan semakin berkurang sedangkan kebutuhan akan minyak terus bertambah. Keadaan diatas juga tidak sesuai dengan kebijakan pemerintah di bidang energi, yang mengusahakan pemakaian bahan bakar minyak bumi yang sehemat-hematnya, mengingat minyak bumi merupakan sumber energi yang tidak dapat diperbaharui. Krisis energi ini menyebabkan manusia beralih pola pikir untuk lebih mengintensifkan penelitian dan penggunaan dari energi yang tidak terbarukan ke energi yang terbarukan. Etanol merupakan bahan bakar beroktan tinggi yang dapat digunakan sebagai peningkat nilai oktan dalam bensin. Etanol mengandung oksigen, sehingga menyempurnakan pembakaran bahan bakar dengan efek positif meminimalkan pencemaran udara. Bahan bakar yang digunakan untuk penelitian ini adalah pertalite murni $\left(\mathrm{E}_{0}\right)$, campuran bioetanol $5 \%$ + pertalite $95 \%\left(\mathrm{E}_{5}\right)$, campuran bioetanol $10 \%$ + pertalite $90 \%\left(\mathrm{E}_{10}\right)$, campuran bioetanol $15 \%$ + pertalite $85 \%\left(\mathrm{E}_{15}\right)$, dan campuran bioetanol $20 \%$ + pertalite $80 \%\left(\mathrm{E}_{20}\right)$. Pencampuran bioetanol pada bahan bakar pertalite dapat meningkatkan performa mesin mencapai titik maksimal pada campuran bahan bakar $\mathrm{E}_{15}$, tetapi pencampuran bioetanol diatas $15 \%$ performa cenderung akan menurun. Untuk mendapatkan performa mesin yang baik, campuran yang paling baik adalah dengan mencampurkan bioetanol $15 \%$ ke dalam pertalite untuk mobil dengan usia diatas 15 tahun. Hal ini didasarkan pada nilai rata-rata torsi dan daya yang dihasilkan oleh masingmasing campuran bahan bakar bioetanol.

Kata kunci : Mobil, Bahan Bakar, Oktan, Pertalite, Bioetanol, Etanol, Performa, Mesin,

\section{PENDAHULUAN}

\section{Latar Belakang}

Dilatar belakangi oleh pemakaian motor bensin dari tahun ke tahun semakin meningkat, hal ini mengakibatkan pemakaian bahan bakar minyak bumi semakin meningkat dan tentu sangat mengkhawatirkan, karena dengan peningkatan pemakaian bahan bakar minyak bumi, maka cadangan minyak bumi akan semakin berkurang sedangkan kebutuhan akan minyak terus bertambah. Keadaan diatas juga tidak sesuai dengan kebijakan pemerintah di bidang energi, yang mengusahakan pemakaian bahan bakar minyak bumi yang sehemat-hematnya, mengingat minyak bumi merupakan sumber energi yang tidak dapat diperbaharui. Krisis energi ini menyebabkan manusia beralih pola pikir 
untuk lebih mengintensifkan penelitian dan penggunaan dari energi yang tidak terbarukan ke energi yang terbarukan.

Salah satu energi tebarukan tersebut adalah berasal dari bio massa yang diproses menjadi etanol. Etanol atau etil alcohol (lebih dikenal sebagai alcohol) adalah cairan berwarna dengan karakteristik antara lain mudah terbakar, larut dalam air, dan jika terjadi pencemaran tidak memberikan dampak lingkungan yang signifikan. Penggunaan etanol sebagai bahan bakar bernilai oktan tinggi atau aditif untuk meningkatkan bilangan oktan pada bahan bakar. Semakin tingginya tingkat permintaan para pengguna kendaraan agar memiliki mobil dengan mesin yang bertenaga namun tetap ramah lingkungan telah menjadi pemicu meningkatnya penggunaan bahan bakar dengan nilai oktan yang tinggi.

Tujuan memilih penelitian ini adalah untuk mengetahui besaran perubahan daya dan torsi pada mesin otto 4 silinder yang dipengaruhi oleh variasi campuran bioetanol pada bahan bakar jenis pertalite, diharapkan hasil dari penelitian ini dapat memberi manfaat dan perbendaharaan pengetahuan di bidang otomotif dan transportasi. Maka, penulis akan mengadakan penelitian yang tertuang dalam laporan "Pengaruh Campuran Bioetanol Pada Pertalite Terhadap Unjuk Kerja (Performa) Mesin Otto 4 Silinder”.

\section{METODOLOGI PENELITIAN}

\section{Metode Pengumpulan Data}

Dalam melaksanakan penelitian, untuk memperoleh hasil yang baik maka diperlukan sejumlah data pendukung agar dapat dilakukan analisa data. Data yang dibutuhkan untuk penelitian ini berdasarkan dari data sekunder dan data primer.

Pengumpulan data dalam penelitian ini dilakukan melalui metode yang digunakan adalah dengan observasi lapangan dengan melakukan uji coba menggunakan sampel yang telah ditentukan yaitu kendaraan bermotor yang akan digunakan sebagai objek penelitian ini. Lokasi pengambilan data bertempat di 
Sekolah Tinggi Transportasi Darat, Gedung Pengujian dan Kontrol Kendaraan Bermotor, Jalan Raya Setu No 89, Cibuntu, Cibitung, Kabupaten Bekasi.

\section{Metode Penelitian}

Penelitian ini merupakan penelitian eksperimen yang dilakukan di Laboratorium Pengujian dan Kontrol Kendaraan Bermotor, dengan tujuan untuk mengetahui sebab akibat yang muncul berdasarkan perubahan perlakuan peneliti. Perubahan perlakuan tersebut adalah pengaruh pemakaian bahan bakar Pertalite $\mathrm{E}_{0}, \mathrm{E}_{5}, \mathrm{E}_{10}, \mathrm{E}_{15}$, dan $\mathrm{E}_{20}$ terhadap perubahan unjuk kerja (performa) mesin pada mobil penumpang yang menggunakan mesin 4 silinder, diukur menggunakan alat Chassis Dynamometer Pro Hofmann.

\section{Sampel Penelitian}

Penelitian ini menggunakan variabel bebas bahan bakar pertalite murni (E0), campuran bioetanol 5\% + pertalite 95\% (E5), campuran bioetanol 10\% + pertalite 90\% (E10), campuran bioetanol 15\% + pertalite 85\% (E15), dan campuran bioetanol 20\% + pertalite $80 \%$ (E20).

Variabel terikat meliputi daya dan torsi pada mobil bermesin bensin 4 silinder dengan kapasitas mesin 1800 cc. Dan variabel kontrol meliputi : a) Mobil mesin bensin 4 silinder dengan kapasitas mesin $1800 \mathrm{cc}$; b) Uji performa terhadap satu variasi campuran dilakukan sebanyak 10 kali; c) Temperatur oli mesin 60-80 ${ }^{\circ} \mathrm{C}$ (temperatur kerja mesin); d) Temperatur udara $25-35{ }^{0} \mathrm{C}$.

\section{Teknik Analisis Data}

Teknik analisis data yang digunakan dalam penelitian ini menggunakan metode statistika deskriptif. Menurut Sugiyono (2009:147), statistik deskriptif adalah statistik yang berfungsi untuk mendeskripsikan atau memberi gambaran terhadap data yang telah terkumpul sebagaimana adanya tanpa bermaksud membuat kesimpulan yang berlaku untuk umum. 


\section{Alat dan Bahan}

1. Alat-alat yang digunakan dalam penelitian ini adalah sebagai berikut:

a. Burret tester (Gelas Ukur), alat untuk menampung bahan bakar.

b. Blower, untuk menjaga suhu kerja mesin.

c. Chassis dynamometer HOFMANN, untuk menguji unjuk kerja (performa) mobil. Dengan spesifikasi teknis:

1) Max pressure air compressor :0,8-1,1 bar

2) Max consumption :850-1100 W

3) Measurement roller dyno : : 0 to $99.9 \%$ corr. 0,1

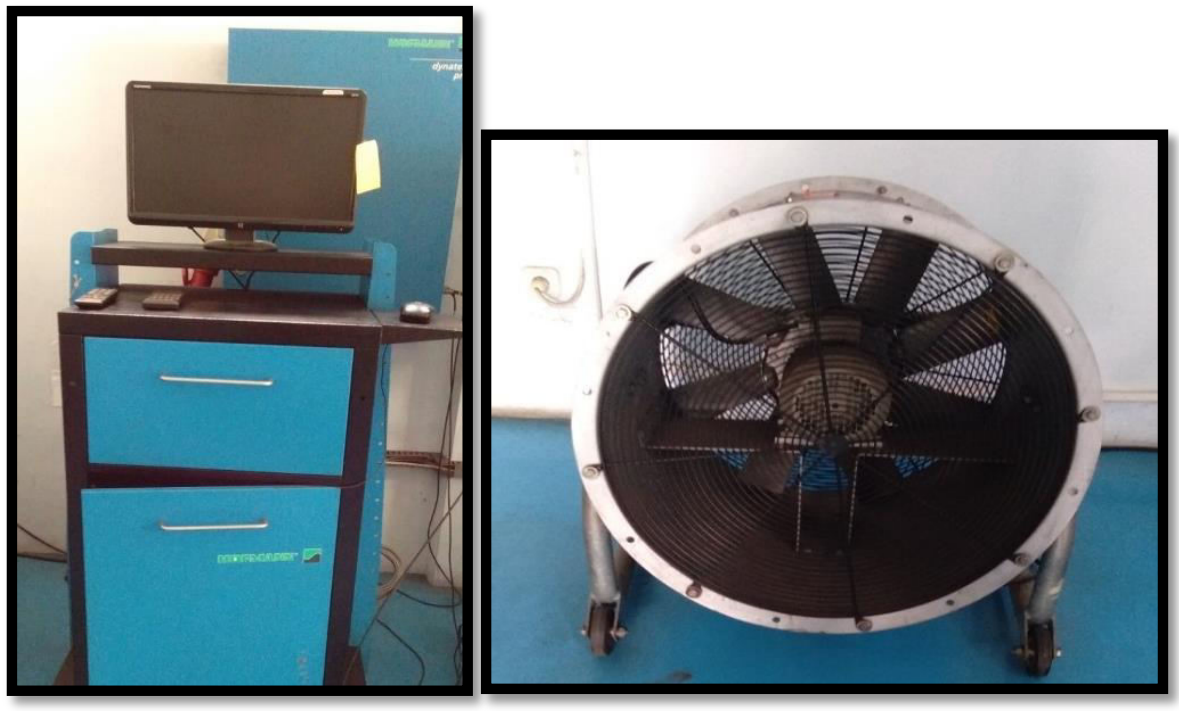

Gambar 1. Alat Ukur Chassis Dynamometer

2. Bahan-bahan yang digunakan dalam penelitian ini adalah sebagai berikut:

a. Mobil Toyota Kijang 2002, dengan spesifikasi :
1) Tipe mesin
: 7K-E 1.8L OHV EFI
2) Jumlah Silinder
: 4 Silinder segaris
3) Diameter $x$ Langkah $: 80.5 \mathrm{~mm} \times 87.5 \mathrm{~mm}$
4) Volume Langkah : $1781 \mathrm{cc}$ 
5) Perbandingan kompresi : $9.0: 1$

6) Berat Kendaraan : $1350 \mathrm{~kg}$

7) Daya maksimum : $86 \mathrm{HP} / 4400 \mathrm{rpm}$

8) Torsi maksimum : :136 Nm/3000 rpm

b. Pertalite diperoleh dari pembelian di SPBU Kalimalang. Bioetanol yang mempunyai grade $98 \%$ yang digunakan untuk bahan bakar.

\section{Pelaksanaan Penelitian}

1. Mempersiapkan alat, bahan dan instrumen penelitian;

2. Pastikan mesin yang akan diukur sudah di-tune up dengan benar.

3. Memasukkan bahan bakar dengan variasi campuran pertalite murni (E0), campuran bioetanol 5\% + pertalite 95\% (E5), campuran bioetanol 10\%+ pertalite $90 \%$ (E10), campuran bioetanol 15\% + pertalite $85 \%$ (E15), dan campuran bioetanol $20 \%$ + pertalite $80 \%$ (E20).

4. Tempatkan roda penggerak kendaraan bermotor yang dijadikan objek penelitian pada roller dyno test..

5. Masukan indikator temperatur oli untuk membaca tekanan oli.

6. Untuk membaca rpm, hubungkan komponen pada gambar di bawah ini pada kendaraan yang akan dilaksanakan dyno test.

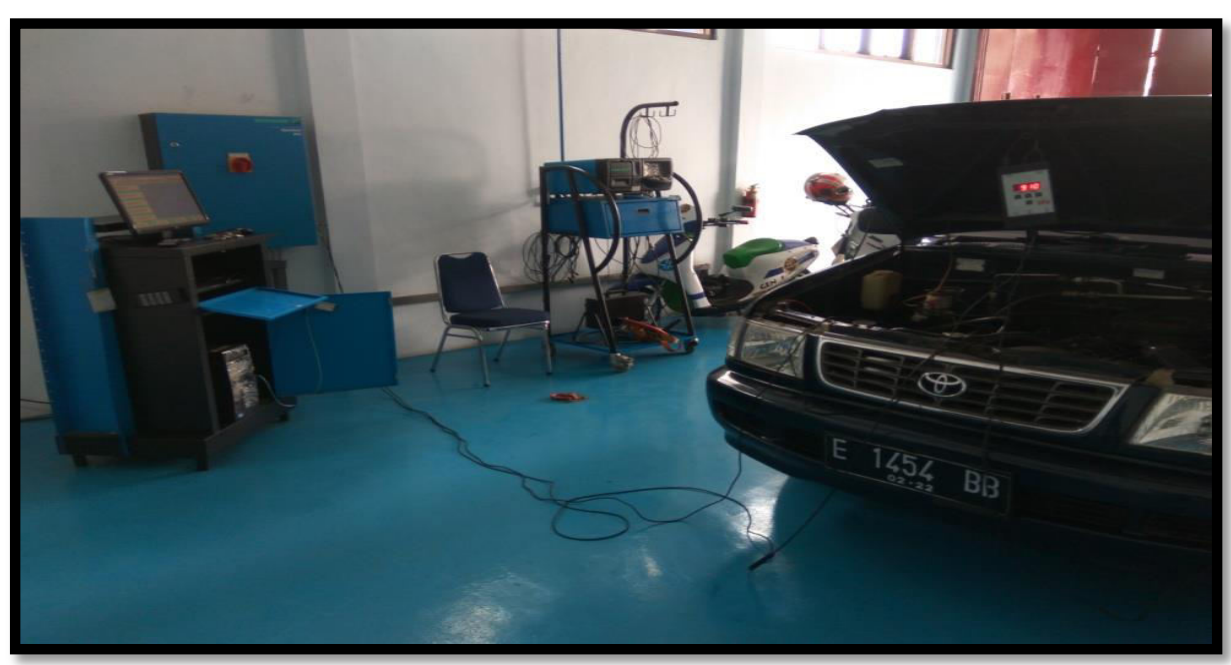

Gambar 2. Pemasangn Komponen Untuk Pembacaan RPM 
7. Hidupkan mesin kendaraan dan blower dyno test.

8. Jika pada tampilan aplikasi dyno test pada komputer berwarna merah, kemudian jalankan roda penggerak kendaraan dengan kecepatan penuh. Lakukan perpindahan sampai percepatan maksimum, dengan percepatan maksimum berada pada angka 5 .

9. Setelah tercapai kecepatan maksimum kendaraan, lepas pedal gas, biarkan roda berhenti dengan sendirinya, jangan menghentikan paksa dengan menggunakan rem, karena kendaraan akan lompat keluar dari roller.

10. Setelah roda berhenti, maka akan muncul hasil pengukuran daya dan cetak hasil pengukuran tersebut.

\section{HASIL DAN PEMBAHASAN}

Parameter yang diukur yaitu daya dan torsi pada setiap variasi campuran bahan bakar. Dari tabel hasil pengumpulan data, maka akan diolah dengan mengambil hasil rata-rata dari masing-masing variasi campuran yakni pertalite murni (E0), campuran bioetanol 5\% + pertalite 95\% (E5), campuran bioetanol $10 \%+$ pertalite $90 \%$ (E10), campuran bioetanol 15\% + pertalite $85 \%$ (E15), dan campuran bioetanol $20 \%$ + pertalite $80 \%$ (E20).

Tabel 1. Hasil Rata-rata Daya dan Torsi pada Semua Variasi Campuran Bioetanol

\begin{tabular}{|l|c|c|}
\hline \multicolumn{1}{|c|}{ Variasi Campuran } & Daya (hp) & Torsi (Nm) \\
\hline Pertalite Murni (E0) & 84.8 & 135.7 \\
\hline Bioetanol 5\% + Pertalite 95\% (E5) & 87.1 & 143.6 \\
\hline Bioetanol 10\% + Pertalite 90\% (E10) & 91.0 & 150.2 \\
\hline Bioetanol 15\% + Pertalite 85\% (E15) & 99.3 & 163.8 \\
\hline Bioetanol 20\% + Pertalite 80\% (E20) & 97.0 & 160.1 \\
\hline
\end{tabular}




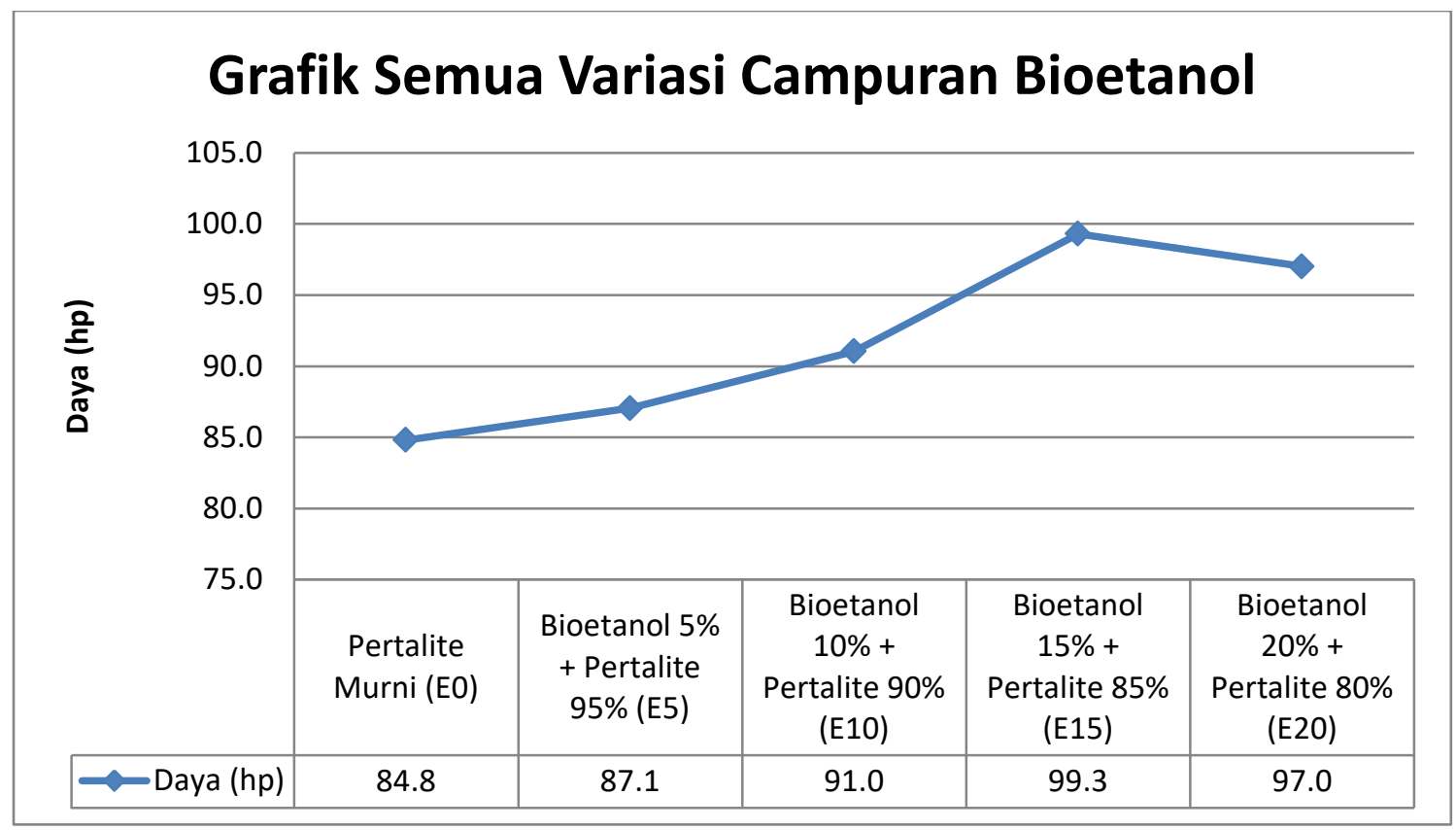

Gambar 2. Grafik Daya Rata-rata pada Semua Variasi Campuran Bioetanol

Berdasarkan gambar 2 di atas, menunjukkan daya yang dihasilkan oleh Pertalite Murni (E0) adalah sebesar $84.8 \mathrm{hp}$, kemudian meningkat pada variasi campuran bahan bakar Bioetanol 5\% + Pertalite 95\% (E5) adalah sebesar $87.1 \mathrm{hp}$. Pada variasi campuran bahan bakar Bioetanol 10\% + Pertalite 90\% (E10) masih terjadi peningkatan daya sebesar $91.0 \mathrm{hp}$, selanjutnya pada variasi campuran bahan bakar Bioetanol 15\% + Pertalite 85\% (E15) diperoleh lonjakan peningkatan daya dengan nilai sebesar $99.3 \mathrm{hp}$.

Dan pada variasi campuran bahan bakar Bioetanol 20\% + Pertalite $80 \%$ (E20) terjadi penurunan nilai daya menjadi sebesar $97.0 \mathrm{hp}$. Penurunan terjadi pada variasi campuran E20, hal ini disebabkan karena kalor meningkat sehingga pembakaran menjadi kurang sempurna. 


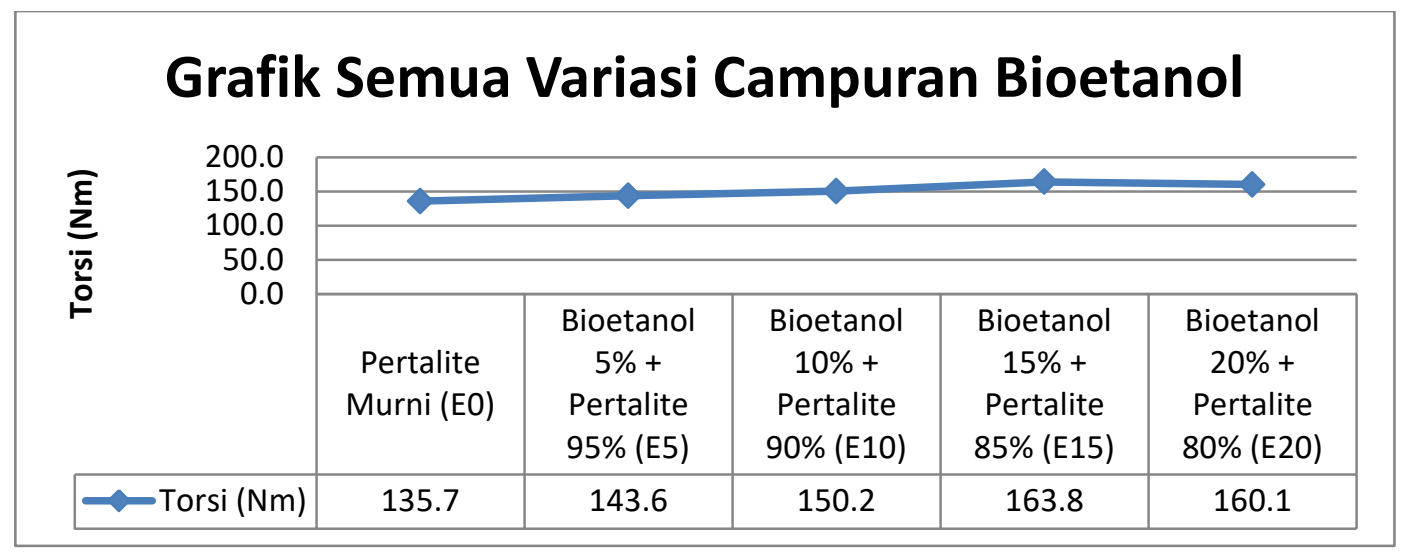

Gambar 3. Grafik Torsi Rata-rata pada Semua Variasi Campuran Bioetanol

Pada gambar 3 di atas, menunjukkan torsi yang dihasilkan oleh Pertalite Murni (E0) adalah sebesar 135.7 Nm, kemudian meningkat pada variasi campuran bahan bakar Bioetanol 5\% + Pertalite 95\% (E5) adalah sebesar 143.6 Nm. Pada variasi campuran bahan bakar Bioetanol 10\% + Pertalite 90\% (E10) masih terjadi peningkatan torsi sebesar $150.2 \mathrm{Nm}$, selanjutnya pada variasi campuran bahan bakar Bioetanol 15\% + Pertalite 85\% (E15) diperoleh lonjakan peningkatan torsi dengan nilai sebesar 163.8 Nm. Dan pada variasi campuran bahan bakar Bioetanol $20 \%+$ Pertalite $80 \%$ (E20) terjadi penurunan nilai torsi menjadi sebesar 160.1 Nm. Penurunan nilai torsi terjadi pada variasi campuran E20, hal ini sejalan dengan penurunan yang tejadi pada daya mobil.

Meningkatnya nilai oktan sangat berpengaruh pada pembakaran, sehingga jika kualitas bahan bakar lebih baik, maka akan terjadi proses pembakaran sempurna. Hal ini sesuai dengan penelitian menurut Winarno (2011:39) yang menyatakan bahwa penambahan bioetanol pada bahan bakar pertamax terhadap unjuk kerja motor bensin pada putaran rendah hingga menengah terjadi peningkatan daya dan torsi. 


\section{DAFTAR PUSTAKA}

Arismunandar, W., 2002, Motor Bakar Torak, Edisi 5, ITB, Bandung.

Arends, BPM, Berenschot, H.,1980, (Alih Bahasa), Motor Bensin, PT. Erlangga, Jakarta.

Heywood, JB., 1988, Internal Combustion Engine Fundamentals, McGraw-Hill, Inc., USA.

Anonim, Manual Book Sepeda Motor Honda Vario, Astra Honda Motor, 2011.

Edward F. Obert, Internal Combustion Engines and Air Pollution, Harper \& Row, Publishers, Inc, 1973.

Erliza Hambali, Siti Mujdalipah, Armansyah Halomoan Tambunan, Abdul Waries Pattiwiri, dan Roy Hendroko. 2007. Teknologi Bioenergi. Jakarta: Agromedia Pustaka.

Kusminingrum Nanny dan G. Gunawan. 2008. Polusi Udara Akibat Aktivitas Kendaraan Bermotor di Jalan Perkotaan Pulau Jawa dan Bali.Bandung : Puslitbang Jalan dan Jembatan.

Michael J Moran dan Howard Shapiro, TermodinamikaTeknik 1, Erlangga.

PT. Astra Daihatsu Motor Training Center, Diktat VVT-i, Jakarta, 2008.

Pulkrabek Willard W, Engineering Fundamentals of The Internal Combustion Engine, Prentice Hall, New Jersey.

Sugiyono. 2009. Metode Penelitian Kuantitatif Kualitatif dan R\&D. Bandung: Alfabeta.

Syahrani, A. 2006. Analisa Kinerja Mesin Bensin Berdasarkan Hasil Uji Emisi. Jurnal SMARTek.

Soedomo, Moestikahadi, Pencemaran Udara, Penerbit ITB, Bandung, 2001. 